glands, the alimentary system, and the respiratory system, and of allergy.

Some of the writing is masterly, the product of minds completely interested in their subjects and able to express their thoughts clearly. There are twenty-nine authors, three of whom are American, while ten are on the active staff of the Hospital for Sick Children, Great Ormond Street. There are I54 well-chosen illustrations, many tables, selected lists of references, and a good index. Faults are few. The printing and binding are good. In short, the authors, editors and publishers have done well. We can confidently recommend the purchase of this volume, it is a sufficient guarantee of the quality of the second.

To pick out merits and demerits is part of the reviewer's function but he cannot feel entirely happy at expressing personal views from the concealment of the editorial shadow. However we (to make no more bones about it) particularly like Denis Browne's notes on congenital deformities, Noah Morris' account of growth and development (but would have liked some diagrams here), McNair Scott's chapter on dehydration, salt-depletion, etc. (with good diagrams), James Crooks' long piece on diseases of the nose, pharynx, larynx and ears, and the chapter headed 'Diseases of the Respiratory System,' by Alan Moncrieff, R. S. Pilcher, and C. Elaine Field. We wish that Crooks had told us what he thought of hormonal sprays for laryngeal papillomata, and it is odd that in a book of this size there are no tables which would enable us to work out an actual diet for a diabetic child. However, there is surprisingly little to cavil at, considering the size and scope of the book.

Crashaw wrote on a prayer book he sent to a lady: 'Lo here a little volume, but large book.' Confronted with large crown octavo, we can hardly use the same phrase, but if we did it would not be entirely inappropriate.

P.R.E.

\section{THE DEVELOPMENT OF INHALATION} ANAESTHESIA

By Barbara M. Duncum, D.Phil. Pp. 640 ; 16 I illustrations. Oxford University Press for the Wellcome Historical Medical Museum. 1947. Price 25s.

It is fitting that this authoritative work was completed at the time when we were celebrating the Centenary Year of Anaesthesia in England. The few histories of anaesthesia previously published laid particular stress on the advances and discoveries in the American States. The work of our own great men, Snow, Simpson, Clover, Hewitt and the many Continental anaesthetists took second place.

Dr. Duncum's history is broad in its scope and unbiased in its opinions. In the Introduction the general trend of anaesthetic practice and teaching is traced against the background of 19 th century social history and world affairs. The chapters that follow contain a detailed account of the many topics thus introduced. This book, which is very easy to read, is well illustrated and contains many extracts from early textbooks and journals on anaesthesia and kindred subjects. It is hoped that Dr. Duncum will, in a subsequent volume, complete the story of anaesthesia during the last half century.

\section{BROMPTON HOSPITAL REPORTS}

Vol. XIv. 1945. Gale \& Polden. 1947. Price Ios.

This slim, black volume contains a valuable collection of articles published in various journals. The thoracic specialist will derive much benefit from rereading these articles and the general practitioner will find here a convenient symposium of recent advances in the medical and surgical treatment of chest diseases.

It is impossible to deal with each individual article, but the reviewer was most interested in the paper on Pulmonary Hydatid Disease by N. R. Barrett and Dillwyn Thomas, and the paper by O. S. Tubbs showing what surgery can offer for the patent ductus arteriosus, infected or noninfected.

This is a most useful book for anyone interested in chest diseases.

\section{HEPARIN IN THE TREATMENT OF THROMBOSIS}

By J. E. Jorpes, M.D. 2nd Edition. Pp. 260. Oxford University Press. Geoffrey Cumberlege. 1946. Price i 8 s.

This monograph has been beautifully printed in Sweden and is a masterly exposition on heparin in all its aspects.

The book starts with a brief history of the discovery and purification of heparin. There follows a good account of its physiological actions, the possible sites of formation and destruction in the body, and the various methods used for standardizing it. There is also a brief account of dicouramin and other anti-coagulant substances.

The most valuable part of this book is an excellent review of the work, mainly carried out in Swedish clinics during recent years, on the clinical application of heparin in thrombosis. Here will be found details of Crafoord's pioneer work on the treatment and prevention of post-operative thrombosis and Bauer's phlebographic study of clotting in the deep calf veins. The value of heparin in retinal thrombosis, cavernous sinus thrombosis and vascular surgery is also reviewed, and finally a critical evaluation of the place that heparin should take in modern hospital practice is given.

T he bibliography is excellent and the whole book is written in clear, simple English which cannot fail to attract the reader. This publication is essential to anybody whose work or interest lies in the field of thrombosis and its treatment by heparin. 